Article

\title{
Carrageenan of Red Algae Eucheuma gelatinae: Extraction, Antioxidant Activity, Rheology Characteristics, and Physicochemistry Characterization
}

\author{
Hoang Thai Ha ${ }^{1}$, Dang Xuan Cuong ${ }^{1,2,3, *}$, Le Huong Thuy ${ }^{4} * \mathbb{D}$, Pham Thanh Thuan ${ }^{5}$, Dang Thi Thanh Tuyen ${ }^{6}$, \\ Vu Thi Mo ${ }^{2,3}$ and Dinh Huu Dong ${ }^{1}$
}

1 Department of Food Technology, Ho Chi Minh City University of Food Industry, Ho Chi Minh 700000, Vietnam; haht@hufi.edu.vn (H.T.H.); dongdh@hufi.edu.vn (D.H.D.)

2 Department of Biology, Graduate University of Science and Technology, VAST, Ha Noi 100000, Vietnam; thaonguyenxanh1607@gmail.com

3 Department of Organic Material from Marine Resource, Nha Trang Institute of Technology Research and Application, VAST, Nha Trang 650000, Vietnam

4 Institute of Biotechnology and Food Technology, Industrial University of Ho Chi Minh City, Ho Chi Minh 700000, Vietnam

5 General Surgery Department, Ninh Thuan Provincial General Hospital, Phan Rang 59000, Vietnam; phamthanhthuan2015@gmail.com

6 Department of Food Science, Nha Trang University, Nha Trang 650000, Vietnam; thanhtuyen151809@gmail.com

* Correspondence: xuancuong@nitra.vast.vn (D.X.C.); lehuongthuy@iuh.edu.vn (L.H.T.); Tel.: +84-905-239-482 (D.X.C.); +84-932-082-199 (L.H.T.)

\section{check for}

updates

Citation: Ha, H.T.; Cuong, D.X.;

Thuy, L.H.; Thuan, P.T.; Tuyen, D.T.T.; Mo, V.T.; Dong, D.H. Carrageenan of Red Algae Eucheuma gelatinae: Extraction, Antioxidant Activity, Rheology Characteristics, and Physicochemistry Characterization. Molecules 2022, 27, 1268. https:// doi.org/10.3390/molecules27041268

Academic Editors: Laura Orian and Giovanni Ribaudo

Received: 31 December 2021

Accepted: 6 February 2022

Published: 14 February 2022

Publisher's Note: MDPI stays neutral with regard to jurisdictional claims in published maps and institutional affiliations.

Copyright: (C) 2022 by the authors. Licensee MDPI, Basel, Switzerland. This article is an open access article distributed under the terms and conditions of the Creative Commons Attribution (CC BY) license (https:// creativecommons.org/licenses/by/ $4.0 /)$.

\begin{abstract}
Carrageenan is an anionic sulfated polysaccharide that accounts for a high content of red seaweed Eucheuma gelatinae. This paper focused on the extraction, optimization, and evaluation of antioxidant activity, rheology characteristics, and physic-chemistry characterization of $\beta$-carrageenan from Eucheuma gelatinae. The extraction and the optimization of $\beta$-carrageenan were by the maceration-stirred method and the experimental model of Box-Behken. Antioxidant activity was evaluated to be the total antioxidant activity and reducing power activity. The rheology characteristics of carrageenan were measured to be gel strength and viscosity. Physic-chemistry characterization was determined, including the molecular weight, sugar composition, function groups, and crystal structure, through GCP, GC-FID, FTIR, and XRD. The results showed that carrageenan possessed antioxidant activity, had intrinsic viscosity and gel strength, corresponding to $263.02 \mathrm{cps}$ and $487.5 \mathrm{~g} / \mathrm{cm}^{2}$, respectively. Antioxidant carrageenan is composed of rhamnose, mannose, glucose, fucose, and xylose, with two molecular weight fractions of $2.635 \times 10^{6}$ and $2.58 \times 10^{6} \mathrm{~g} / \mathrm{mol}$, respectively. Antioxidant carrageenan did not exist in the crystal. The optimization condition of antioxidant carrageenan extraction was done at $82.35^{\circ} \mathrm{C}$ for $115.35 \mathrm{~min}$ with a solvent-to-algae ratio of $36.42(v / w)$. At the optimization condition, the extraction efficiency of carrageenan was predicted to be $87.56 \pm 5.61(\%)$, the total antioxidant activity and reducing power activity were predicted to $71.95 \pm 5.32$ (mg ascorbic acid equivalent/g DW) and $89.84 \pm 5.84\left(\mathrm{mg} \mathrm{FeSO}_{4}\right.$ equivalent/g DW), respectively. Purity carrageenan content got the highest value at $42.68 \pm 2.37$ (\%, DW). Antioxidant carrageenan from Eucheuma gelatinae is of potential use in food and pharmaceuticals.
\end{abstract}

Keywords: $\beta$-carrageenan; antioxidant activity; Box-Behken; extraction; Eucheuma gelatinae; physicchemistry; rheology

\section{Introduction}

Eucheuma gelatinae belongs to the Solieriaceae family, specifically the Rhodophyta division, and is a commonly popular marine plant acting as the material for processing $\beta$-carrageenan that is widely used in food, functional foods, and pharmaceuticals. The 
Eucheuma gelatinae species is a small individual size and lives in dead coral areas. Currently, the demand for carrageenan increases more in the commercial rhodophytes and plays a vital role in the world [1-3]. The Eucheuma species was the most farmed red algae, with 10.2 million tonnes in 2015, cultured in Korea, the Philippines, Malaysia, and China as the main algae species [4]. There were about 30,000 tons of cottonii (Eucheuma alvarezii Doty), 6000 tons of spinosum (Eucheuma denticulatum [Burman] Collins \& Hervey), and 100 tons of gelatinae (Eucheuma gelatinae [Esper] J. Agardh) farmed for producing $\kappa$-carrageenan, $\iota$-carrageenan, and a mixture of $\gamma-, \beta$ - and $\kappa$-carrageenans [5], respectively.

Carrageenan is a galactan polysaccharidesand exists in the intercellular matrix of red algae. Carrageenan possesses numerous various bioactivities, for instance, anticoagulant [6], antiviral [7], antithrombotic [8], antibacterial [9], cholesterol-lowering [10], antitumor [11], immunomodulatory [12], and antihyperlipidemic [13]. It is also used in the treatment of stomach ulcers [14], and as an antioxidant. The bioactivity of carrageenan was clearly both in vitro and in vivo, and led to the potential promising in developing therapeutic agents. Among those biological activities, the antioxidant activity of carrageenan is most remarkable because antioxidants will eliminate free radicals and contribute to improving resistance and minimizing diseases in the human body. Therefore, carrageenan has potential in functional foods and pharmaceuticals, and is commonly applied in the food and pharmaceutical industries, and is used primarily for drug delivery (tablets, suppositories, fast-dissolving insert, beads, pellets, films, oral suspensions, micro/nanoparticles, floating model, intranasal system, wafers, hydrogel, and tissue engineering (bone or cartilage, and 3-D bioprinting applications) [15] in the latter. Most publications are mainly on kappa carrageenan from Eucheuma denticulatum and Kappaphycus alverazii.

Nowadays, there are numerous different methods for carrageenan extraction, for example, enzyme-assisted extraction [16], maceration [17], stirring soak [18], pressurizedassisted maceration [19], ultrasound-assisted [20], microwave-assisted [21] and extraction optimization [22]. The results on carrageenan from Eucheuma gelatinae were less and did not present the content, antioxidant activity, rheological and physicochemical properties of carrageenan from Eucheuma gelatinae, especially species grown in Vietnam. Carrageenan application development in functional foods and pharmaceuticals, the control of extraction conditions, the extraction optimization of multi-objective functions including refined carrageenan content, the antioxidant activity, rheology, and the physicochemical properties of carrageenan all demonstrate its essential role.

Therefore, the study focuses on the extraction and optimization of antioxidant carrageenan extracting from Eucheuma gelatinae grown in Vietnam, and the evaluation of its antioxidant activity, rheology characteristics, and physiochemistry properties.

\section{Results}

\subsection{Extraction of Antioxidant Carrageenan}

2.1.1. Purity Carrageenan Content

The purity of carrageenan content varied from $23.41 \pm 1.27$ to $41.94 \pm 3.05(\%$, DW) in the range of the extraction condition as described in Section 4.3 (Table 1). Solvent ( $\mathrm{pH}$ 7) caused the highest purity carrageenan content, compared to other $\mathrm{pH}$ solvents at the same condition. The significant difference in the purifying carrageenan content $(p<0.05)$ occurred as a $\mathrm{pH}$ solvent over 8 . Pure carrageenan content was the highest at $100{ }^{\circ} \mathrm{C}$, compared to others. However, using an extracting temperature from 80 to $100{ }^{\circ} \mathrm{C}$ affected non-significantly the pure carrageenan content $(p>0.05)$, except for the temperature, which lowered to $80^{\circ} \mathrm{C}$. Purity carrageenan content was in the range of $33.77 \pm 1.55$ to $39.62 \pm 1.82(\%, \mathrm{DW})$ as surveying the extracting temperature. Pure carrageenan content got $32.45 \pm 1.62(\%, \mathrm{DW})$ and $39.52 \pm 2.11(\%, \mathrm{DW})$ at the extracting time of $30 \mathrm{~min}$ and $120 \mathrm{~min}$, respectively. The difference in purity carrageenan content did not occur while the extraction time was from 60 to $120 \mathrm{~min}(p>0.05)$ (Table 1$)$. The highest purity carrageenan content was $41.02 \pm 3.52(\%$, DW) for the extracting time of $90 \mathrm{~min}$. The solvent-to-algae ratio was significantly affected purity carrageenan content $(p<0.05)$ as lower than $30 / 1$ 
$(v / w)$. The purity carrageenan content of $42.68 \pm 2.37$ was found at the solvent-to-algae ratio of $40 / 1(v / w)$, and this was the highest value compared to other conditions.

Table 1. Effect of the extraction condition on purity carrageenan content and its antioxidant activity.

\begin{tabular}{|c|c|c|c|c|c|c|c|}
\hline Std & $\mathrm{pH}$ & $\begin{array}{c}\text { Extracting } \\
\text { Temperature } \\
\left({ }^{\circ} \mathrm{C}\right)\end{array}$ & $\begin{array}{c}\text { Extracting } \\
\text { Time (min) }\end{array}$ & $\begin{array}{c}\text { Solvent-to- } \\
\text { algae Ratio } \\
(v / w)\end{array}$ & $\begin{array}{c}\text { Purity } \\
\text { Carrageenan } \\
\text { Content } \\
(\%, D W)\end{array}$ & $\begin{array}{l}\text { Total Antioxidant } \\
\text { Activity } \\
\text { (mg Ascorbic Acid } \\
\text { Equivalent/g DW) }\end{array}$ & $\begin{array}{c}\text { Reducing Power } \\
\text { Activity } \\
\text { (mg FeSO } \\
\text { Equivalent/g } \\
\text { DW) }\end{array}$ \\
\hline \multirow{4}{*}{ I } & 7 & 80 & 60 & $30 / 1$ & $36.09 \pm 1.21^{a}$ & $24.58 \pm 1.15^{\mathrm{a}}$ & $26.75 \pm 1.98^{a}$ \\
\hline & 8 & 80 & 60 & $30 / 1$ & $34.57 \pm 1.42^{\mathrm{a}}$ & $19.73 \pm 2.01^{b}$ & $23.29 \pm 2.44^{\mathrm{ac}}$ \\
\hline & 9 & 80 & 60 & $30 / 1$ & $27.28 \pm 1.03^{b}$ & $15.62 \pm 2.19^{b}$ & $27.84 \pm 2.71^{\mathrm{a}}$ \\
\hline & 10 & 80 & 60 & $30 / 1$ & $23.41 \pm 1.27^{c}$ & $10.04 \pm 1.68^{c}$ & $20.61 \pm 2.52^{b c}$ \\
\hline \multirow{4}{*}{ II } & 7 & 70 & 60 & $30 / 1$ & $33.77 \pm 1.55^{\mathrm{a}}$ & $19.32 \pm 1.92^{\mathrm{a}}$ & $20.57 \pm 2.03^{a}$ \\
\hline & 7 & 80 & 60 & $30 / 1$ & $36.09 \pm 1.47^{\mathrm{ab}}$ & $24.58 \pm 1.15^{b}$ & $26.75 \pm 1.98^{b}$ \\
\hline & 7 & 90 & 60 & $30 / 1$ & $38.58 \pm 1.69^{b}$ & $27.29 \pm 2.75^{b c}$ & $29.52 \pm 3.01^{b}$ \\
\hline & 7 & 100 & 60 & $30 / 1$ & $39.62 \pm 1.82^{b c}$ & $29.31 \pm 2.48^{c}$ & $30.59 \pm 3.26^{b}$ \\
\hline \multirow{4}{*}{ III } & 7 & 90 & 30 & $30 / 1$ & $32.45 \pm 1.62^{\mathrm{a}}$ & $19.05 \pm 2.23^{a}$ & $23.17 \pm 1.78^{a}$ \\
\hline & 7 & 90 & 60 & $30 / 1$ & $38.58 \pm 1.69^{b}$ & $27.29 \pm 2.75^{b}$ & $29.52 \pm 3.01^{b}$ \\
\hline & 7 & 90 & 90 & $30 / 1$ & $41.02 \pm 3.52^{b}$ & $28.58 \pm 3.10^{b}$ & $30.09 \pm 2.67^{b}$ \\
\hline & 7 & 90 & 120 & $30 / 1$ & $39.52 \pm 2.11^{b}$ & $30.76 \pm 3.21^{b}$ & $32.68 \pm 3.24^{b}$ \\
\hline \multirow{4}{*}{ IV } & 7 & 90 & 90 & $20 / 1$ & $30.14 \pm 2.38^{a}$ & $20.37 \pm 1.92^{a}$ & $25.73 \pm 2.75^{a}$ \\
\hline & 7 & 90 & 90 & $30 / 1$ & $41.02 \pm 3.52^{b}$ & $28.58 \pm 3.10^{b}$ & $30.09 \pm 2.67^{\mathrm{ab}}$ \\
\hline & 7 & 90 & 90 & $40 / 1$ & $42.68 \pm 2.37^{b}$ & $29.72 \pm 3.22^{b}$ & $34.67 \pm 2.78^{b c}$ \\
\hline & 7 & 90 & 90 & $50 / 1$ & $41.94 \pm 3.05^{b}$ & $30.04 \pm 2.57^{b}$ & $36.25 \pm 3.01^{\mathrm{cd}}$ \\
\hline
\end{tabular}

Note: Std I, II, III, and IV included four lines. Letters a, b, c, and d in each column exhibited a significant difference in the column of each Std with $p<0.05, n=3$.

\subsubsection{Antioxidant Activity \\ Total Antioxidant Activity}

The total antioxidant activity was in the range of $10.04 \pm 1.68$ to $30.76 \pm 3.21$ (mg ascorbic acid equivalent/g DW) when the survey of the extraction conditions and the change of total antioxidant activity were significant $(p<0.05)$. The difference in solvent $\mathrm{pH}$ led to the difference in total antioxidant activity $(p<0.05)$, except for solvents $\mathrm{pH} 8$ and 9. The total antioxidant activity got the highest value of $24.58 \pm 1.15$ (mg ascorbic acid equivalent/g DW) at solvent $\mathrm{pH} 7$ when compared to other solvents. The extracting temperature affected total antioxidant activity $(p<0.05)$ when the temperature increased from $70,80^{\circ} \mathrm{C}$ to $10{ }^{\circ} \mathrm{C}$. The non-significant difference in total antioxidant activity occurred when the extracting temperature increased from 80 to $90^{\circ} \mathrm{C}$ and 90 to $100{ }^{\circ} \mathrm{C}$. However, the total antioxidant activity was still evaluated highest with the value of $29.31 \pm 2.48$ (Table 1).

The extracting time of carrageenan from 60 to $120 \mathrm{~min}$ did not significantly affect total antioxidant activity $(p<0.05)$; the extracting time of $30 \mathrm{~min}$ impacted to significant $(p<0.05)$, compared to other the extracting time. The highest total antioxidant activity was for 120 min compared to other extraction conditions.

Under the impact of the solvent-to-algae ratio, total antioxidant activity varied from $20.37 \pm 1.92$ to $30.04 \pm 2.57$ (mg ascorbic acid equivalent/g DW), corresponding to the solvent-to-algae ratio of $20 / 1$ and $50 / 1(v / w)$. However, the difference in total antioxidant activity only occurred $(p<0.05)$ when the solvent-to-algae ratio was lower than $30 / 1(v / w)$ in comparison to other solvent-to-algae ratios.

Reducing Power Activity

Reducing power activity changed from $20.57 \pm 2.03$ to $36.25 \pm 3.01\left(\mathrm{mg} \mathrm{FeSO}_{4}\right.$ equivalent/g DW) under the impact of other extraction conditions. Reducing power activity got the highest value of $27.84 \pm 2.71$ (mg FeSO 4 equivalent/g DW) at solvent $\mathrm{pH}$ 9, but was not a significant difference from solvent $\mathrm{pH} 7$ and 8 . Reducing power activity was 
the lowest, corresponding to $20.61 \pm 2.52\left(\mathrm{mg} \mathrm{FeSO}_{4}\right.$ equivalent/g DW) at solvent $\mathrm{pH}$ 10 . The extracting temperature only led to a significant difference $(p<0.05)$ in reducing power activity when the temperature was below $80^{\circ} \mathrm{C}$, compared to other temperatures. The reducing power activity of $30.59 \pm 3.26\left(\mathrm{mg} \mathrm{FeSO}_{4}\right.$ equivalent/g DW) was the highest value, compared to 70 to $90{ }^{\circ} \mathrm{C}$. The reducing power activity $\left(32.68 \pm 3.24, \mathrm{mg} \mathrm{FeSO}_{4}\right.$ equivalent/g DW) was highest for the extracting time of 120 min compared to other times (Table 1). The reducing power activity was not significantly different, compared at 60 and $90 \mathrm{~min}$. The lowest reducing power activity $\left(23.17 \pm 1.78, \mathrm{mg} \mathrm{FeSO}_{4}\right.$ equivalent/g DW) exhibited a significant difference $(p<0.05)$ in comparison to other extracting times.

Under the impact of the solvent-to-algae ratios, the reducing power activity varied from $25.73 \pm 2.75$ to $36.25 \pm 3.01$ (mg FeSO 4 equivalent/g DW). A significant difference did not occur $(p>0.05)$ between the solvent-to-algae ratio of $20 / 1$ and $30 / 1(v / w), 30 / 1$ and 40/1 $(v / w)$, and $40 / 1$ and $50 / 1(v / w)$. The reducing power activity reached the highest and lowest value when the solvent-to-algae ratio was $50 / 1$ and $20 / 1(v / w)$, respectively.

\subsubsection{Correlation between Carrageenan Content and Antioxidant Activity}

Purity carrageenan content strongly correlated to total antioxidant activity and weakly to reducing power activity, corresponding to 0.97 and 0.41 when the impact survey of solvent $\mathrm{pH}$ on purity carrageenan content and antioxidant activity was added. There is a strong correlation between purity carrageenan content and antioxidant activity $\left(R^{2}>0.9\right)$, especially total antioxidant activity (0.99), and reducing power activity (0.97) as with the extracting temperatures survey. The total antioxidant activity and reducing power activity strongly correlated to the purity carrageenan content, corresponding to 0.94 and 0.91 , respectively, as the extracting time survey. A strong correlation was found between purity carrageenan content and antioxidant activity, as the survey of the solvent-to-algae ratio corresponded to 0.99 (total antioxidant activity) and 0.88 (reducing power activity), respectively.

\subsection{Optimization of Antioxidant Carrageenan}

\subsubsection{Analysis of Optimization Model}

According to the study type of response surface with the design type of Box-Behnken on the quadratic model and randomized subtype, the results showed the distribution of the target functions were focusing on the centre of the survey interval, compared with the boundary region. The fit optimization model of $Y_{1}$ function was the quadratic model $(p=0.0001<0.05)$ with non-significant lack-of-fit $(p=0.08>0.05)$ and adjusted $R^{2}(0.95)$. Response surface $Y_{1}$ had a standard deviation (SD) of 5.61 and coefficient of variation $(\mathrm{C} . \mathrm{V} \%)$ of 13.51. Response surface $Y_{2}$ was the model quadratic $(p=0.0002<0.05)$, compared to the model of 2FI, linear, and cubic. SD and C.V\% of $Y_{2}$ were 2.53 and 15.8 , respectively. The lack-of-fit of model $Y_{2}(p=0.43>0.05)$ was non-significant, and its adjusted $\mathrm{R}^{2}$ got 0.94 . Sequential $p$-value and adjusted $\mathrm{R}^{2}$ of the response surface $Y_{3}$ corresponded to the one of response surface $Y_{1}$. The lack of fit of model $Y_{3}$ had a $p$-value of 0.1 . The quadratic model $Y_{3}$ got a C.V\% of 13.74 and SD of 2.53 .

The response surface $Y_{1}$ was in the range of 15.82 to 88.24 (\%) and got the average value of $41.52 \pm 5.61(\%)$. The response surface $Y_{2}$ changed in the range of values (5.11 to $36.20 \mathrm{mg}$ ascorbic acid equivalent/g DW), and its average value got $16.03 \pm 2.53$ (mg ascorbic acid equivalent/g DW). The value range of response surface $Y_{3}$ varied from 5.94 to 39.53 ( $\mathrm{mg} \mathrm{FeSO}_{4}$ equivalent/g DW), with the average value of $18.43 \pm 2.53\left(\mathrm{mg} \mathrm{FeSO}_{4}\right.$ equivalent/g DW) (Table 2). 
Table 2. The experiment results of the optimization design according to the Box-Behnken model.

\begin{tabular}{ccccccc}
\hline Std & $\boldsymbol{X}_{\mathbf{1}}$ & $\boldsymbol{X}_{\mathbf{2}}$ & $\boldsymbol{X}_{\mathbf{3}}$ & $\boldsymbol{Y}_{\mathbf{1}}$ & $\boldsymbol{Y}_{\mathbf{2}}$ & $\boldsymbol{Y}_{\mathbf{3}}$ \\
\hline 1 & 70 & 30 & 35 & 23.56 & 9.02 & 10.48 \\
2 & 100 & 30 & 35 & 27.74 & 10.60 & 12.30 \\
3 & 70 & 120 & 35 & 30.40 & 11.61 & 13.48 \\
4 & 100 & 120 & 35 & 38.24 & 14.59 & 16.94 \\
5 & 70 & 75 & 20 & 22.18 & 8.47 & 9.83 \\
6 & 100 & 75 & 20 & 24.49 & 9.35 & 10.87 \\
7 & 70 & 75 & 50 & 13.40 & 5.11 & 5.94 \\
8 & 100 & 75 & 50 & 49.79 & 19.01 & 22.11 \\
9 & 85 & 30 & 20 & 15.82 & 6.04 & 7.00 \\
10 & 85 & 120 & 20 & 41.01 & 15.66 & 18.19 \\
11 & 85 & 30 & 50 & 31.42 & 12.00 & 13.92 \\
12 & 85 & 120 & 50 & 45.28 & 17.30 & 20.07 \\
13 & 85 & 75 & 35 & 88.24 & 33.71 & 37.43 \\
14 & 85 & 75 & 35 & 86.97 & 31.72 & 39.53 \\
15 & 85 & 75 & 35 & 84.30 & 36.20 & 38.32 \\
\hline
\end{tabular}

Note: Values expressed as mean value, $n=3$.

After ANOVA analysis for three response models, the results showed the solvent-tomaterial ratio had a non-significant effect on all response surfaces because their $p$-value was $0.9527,0.9606$, and 0.9521 , corresponding to surface $Y_{1}, Y_{2}$, and $Y_{3}$, respectively. Interaction factors of $x_{1} x_{2}$ and $x_{2} x_{3}$ possessed a $p$-value higher than 0.05 , showing that these interaction factors did not affect the response surfaces (Table 3 ). The results also showed the coding variable equation of response surface $Y_{1}, Y_{2}$, and $Y_{3}$, as follows:

$$
\begin{aligned}
& Y_{1}=74.17+37.02 x_{1}-44.98 x_{2}-0.1796 x_{3}+2.03 x_{1} x_{2}+11.36 x_{1} x_{3}-4.72 x_{2} x_{3}-55.50 x_{1}{ }^{2}-70.28 x_{2}{ }^{2}-27.82 x_{3}{ }^{2} \\
& Y_{2}=28.93+14.51 x_{1}-18.11 x_{2}-0.0675 x_{3}+0.7778 x_{1} x_{2}+4.34 x_{1} x_{3}-1.80 x_{2} x_{3}-21.94 x_{1}{ }^{2}-28.00 x_{2}{ }^{2}-11.05 x_{3}{ }^{2} \\
& Y_{3}=32.94+16.44 x_{1}-20.04 x_{2}-0.0821 x_{3}+0.9111 x_{1} x_{2}+5.04 x_{1} x_{3}-2.10 x_{2} x_{3}-24.65 x_{1}{ }^{2}-31.28 x_{2}{ }^{2}-12.37 x_{3}{ }^{2}
\end{aligned}
$$

Table 3. The basic parameters of the response surface equation.

\begin{tabular}{cccccccccc}
\hline \multirow{2}{*}{ Source } & \multicolumn{3}{c}{ Response Surface $\boldsymbol{Y}_{\mathbf{1}}$} & \multicolumn{3}{c}{ Response Surface $\boldsymbol{Y}_{\mathbf{2}}$} & \multicolumn{3}{c}{ Response Surface $\boldsymbol{Y}_{\mathbf{3}}$} \\
\cline { 2 - 10 } & $\boldsymbol{p}$-Value & CE & SE & $p$-Value & CE & SE & $p$-Value & CE & SE \\
\hline Model & 0.0007 & 74.17 & 3.02 & 0.0014 & 28.93 & 1.36 & 0.0008 & 32.94 & 1.36 \\
$x_{1}-X_{1}$ & 0.0004 & 37.02 & 4.47 & 0.0008 & 14.51 & 2.02 & 0.0004 & 16.44 & 2.02 \\
$x_{2}-X_{2}$ & 0.0018 & -44.98 & 7.45 & 0.0030 & -18.11 & 3.36 & 0.0019 & -20.04 & 3.36 \\
$x_{3}-X_{3}$ & 0.9527 & -0.1796 & 2.88 & 0.9606 & -0.0675 & 1.30 & 0.9521 & -0.0821 & 1.30 \\
$x_{1} x_{2}$ & 0.7575 & 2.03 & 6.23 & 0.7932 & 0.7778 & 2.81 & 0.7591 & 0.9111 & 2.81 \\
$x_{1} x_{3}$ & 0.0288 & 11.36 & 3.74 & 0.0499 & 4.34 & 1.69 & 0.0305 & 5.04 & 1.69 \\
$x_{2} x_{3}$ & 0.3590 & -4.72 & 4.68 & 0.4325 & -1.80 & 2.11 & 0.3652 & -2.10 & 2.11 \\
$x_{1}^{2}$ & 0.0001 & -55.50 & 5.19 & 0.0002 & -21.94 & 2.34 & 0.0001 & -24.65 & 2.34 \\
$x_{2}^{2}$ & 0.0003 & -70.28 & 8.11 & 0.0006 & -28.00 & 3.66 & 0.0004 & -31.28 & 3.66 \\
$x_{3}^{2}$ & 0.0002 & -27.82 & 2.92 & 0.0004 & -11.05 & 1.32 & 0.0002 & -12.37 & 1.32 \\
\hline
\end{tabular}

SE: Standard error; CE: Coefficient estimate.

The importance of response surfaces was equal, and the extraction optimization of antioxidant carrageenan via the software Design-Expert version 13 showed the optimization point of $82.35^{\circ} \mathrm{C}, 115.35 \mathrm{~min}$, and $36.42(\mathrm{v} / \mathrm{w})$ with the overlay figure of response surfaces (Figure 1d). Antioxidant carrageenan was the white color and yarn type in the optimization point (Figure 1e,f). At the optimization condition, response surfaces $Y_{1}, Y_{2}$, and $Y_{3}$ were predicted to get the average value of $87.56 \pm 5.61(\%), 71.95 \pm 5.32(\mathrm{mg}$ ascorbic acid equivalent/g DW), and $89.84 \pm 5.84\left(\mathrm{mg} \mathrm{FeSO}_{4}\right.$ equivalent/g DW), respectively. Response surfaces were the spherical surface (Figure 1a-c). 


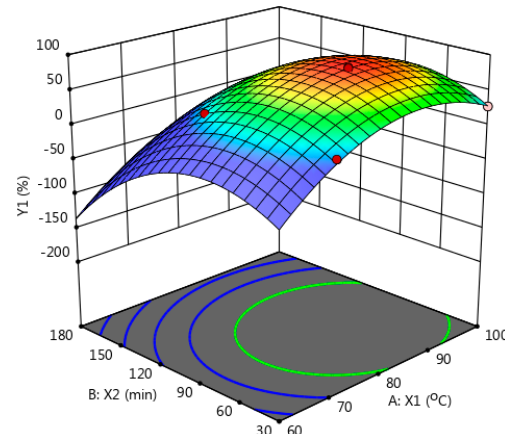

(a)

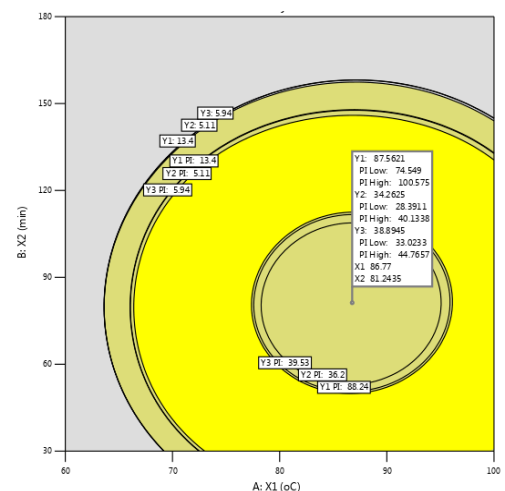

(d)

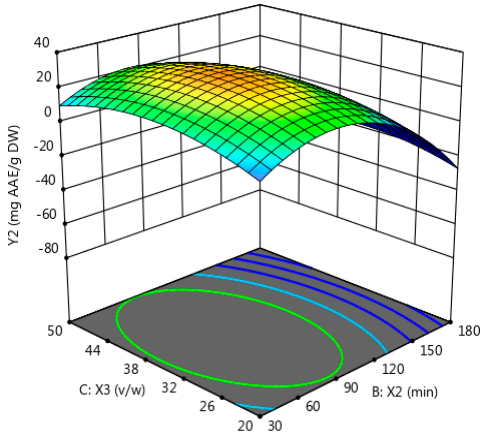

(b)

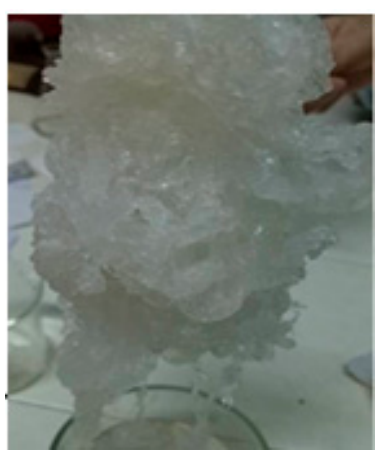

(e)

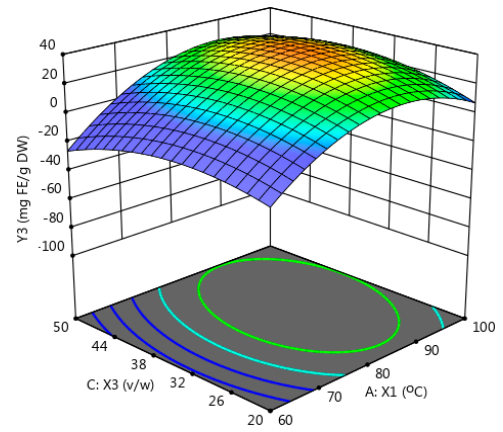

(c)

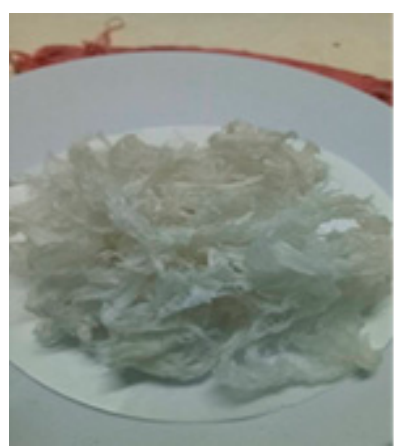

(f)

Figure 1. Response surface, overlay surface and antioxidant carrageenan: (a) Response surface of $Y_{1}$; (b) Response surface of $Y_{2} ;$ (c) Response surface of $Y_{3} ;$ (d) Overlay surface of $Y_{1}, Y_{2}$, and $Y_{3}$; (e) Carrageenan after precipitation using 96\% ethanol; (f) Carrageenan after drying.

\subsubsection{Test of Optimization Model by the Experiment}

Following the experiment on the optimization condition and the correlation analysis between the actual target functions and the predicted target function, the results showed the strong correlation between the experiment and the prediction (Figure 2). The experiment value of the target functions corresponded to $86.52\left(Y_{1}\right)$ (Figure 2a), $87.69\left(Y_{2}\right)$ (Figure 2b), and $85.73 \%\left(Y_{3}\right)$ (Figure 2c) when compared to the predicted target functions by the software Design Expert version 13.

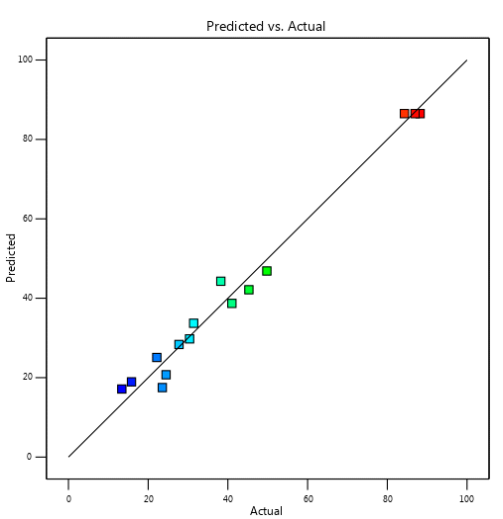

(a)

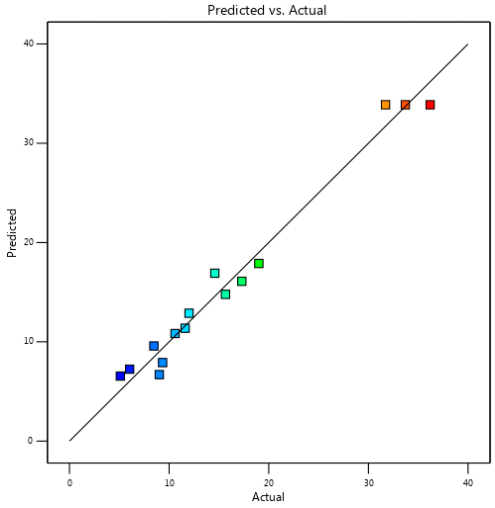

(b)

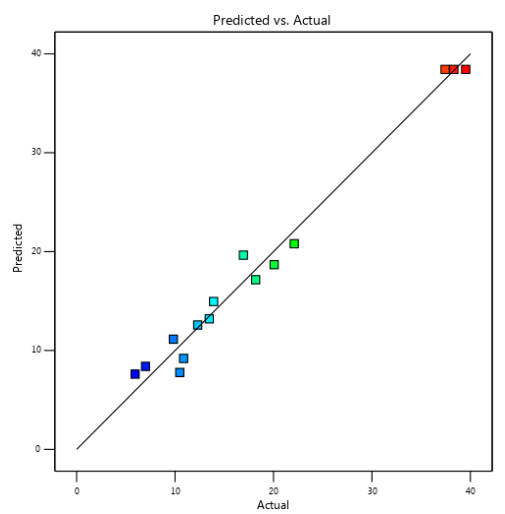

(c)

Figure 2. The correlation between predicted target function and actual target function: (a) $Y_{1}$, (b) $Y_{2}$, (c) $Y_{3}$, respectively. 


\subsection{Characteristics of Rheology and Physical-Chemistry of Antioxidant Carrageenan}

\subsubsection{Rheological Characteristic of Antioxidant Carrageenan}

Intrinsic viscosity and gel strength of antioxidant carrageenan had a value of 263.02 cps and $487.5 \mathrm{~g} / \mathrm{cm}^{2}$, respectively.

\subsubsection{Physical-Chemistry Characteristics of Antioxidant Carrageenan}

Different sugars were found in antioxidant carrageenan, such as rhamnose, mannose, glucose, fucose, and xylose. These sugars got the value of 59.16, 52.63, 78.20, 20.24, and 96.98, respectively. Galactose was not detected in antioxidant carrageenan (Figure 3).

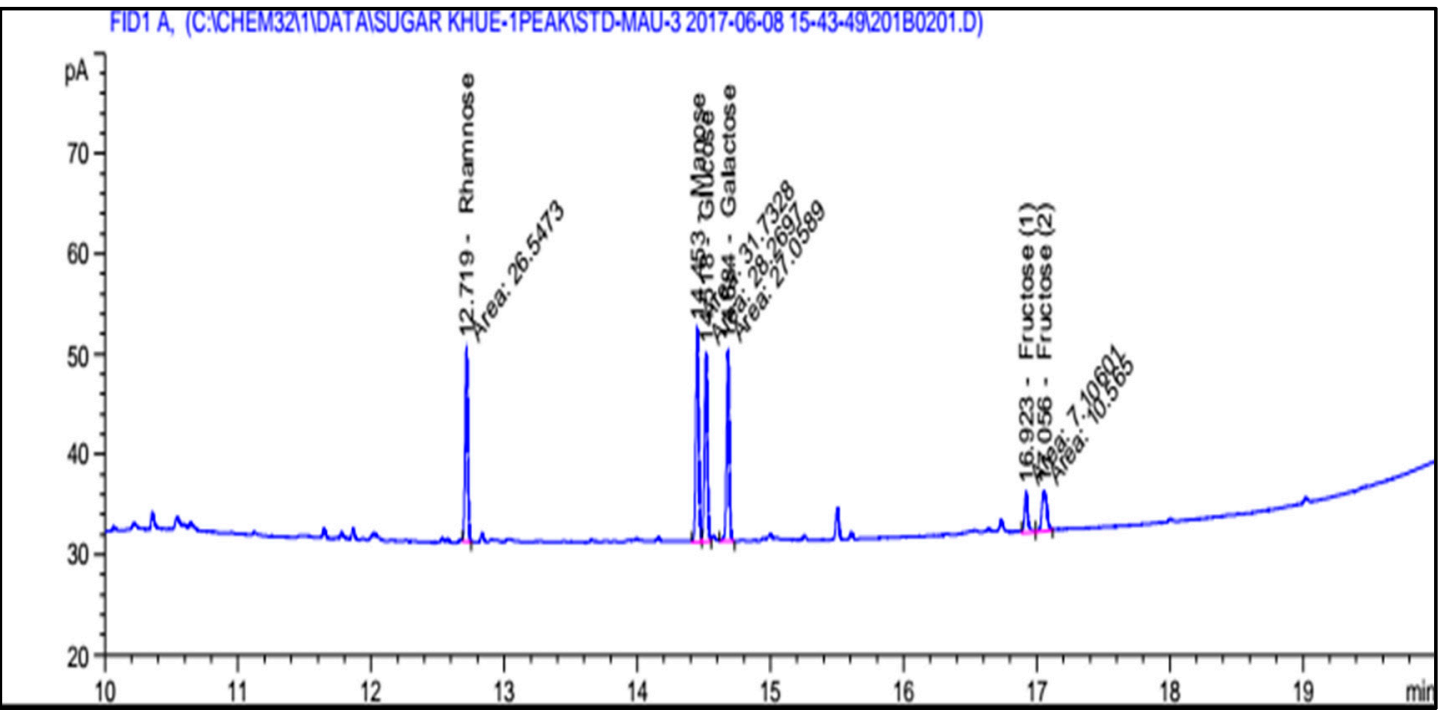

Figure 3. Sugar composition of antioxidant carrageenan.

The FTIR method utilizes the material's light absorption by manipulating how different molecular compounds respond to infrared light to determine the analyzed material's structure. This method is also known as absorption spectroscopy. It is applied in various ways, including light beams of a limited frequency group or using monochromatic light. This technique exploits that the fact that each frequency responds differently to the material and works by using more than one different frequency in the beam. In this way, the composition of unknown material is precisely determined. FTIR spectroscopy offers the advantage of measuring a small sample (a few milligrams or milliliters) in the least amount of time. FTIR analysis in the spectrum range of 580-3420 cm $\mathrm{cm}^{-1}$ showed different peaks, such as 3416.64, 2926.42, 1722.49, 1643.63, 1417.96, 1376.90, 1264.34, 1161.71, 1071.64, 845.86, and $582.00 \mathrm{~cm}^{-1}$ occurring in the FTIR of antioxidant carrageenan extracting from Eucheuma gelatinae grown in Vietnam. The things showed the functional groups, for example, $-\mathrm{OH}, \mathrm{C}-$ $\mathrm{H}, \mathrm{C}=\mathrm{O}, \mathrm{NH}_{2}$ deformation, $\mathrm{C}-\mathrm{O}-\mathrm{H}$ stretch or $\mathrm{C}-\mathrm{O} / \mathrm{C}-\mathrm{H}$ bending, $\mathrm{C}-\mathrm{O}$ or $\mathrm{CH}_{3}$ deformation, alkyl ketone or $\mathrm{C}-\mathrm{O}-\mathrm{C}$ stretch, alkylamine, sulphation of $\mathrm{C} 4$ of the /3-1,3-linked residue, and S-O-S bending (Figure S1). The peak of $842.89 \mathrm{~cm}^{-1}$ exhibited the $\mathrm{C}-\mathrm{O}-\mathrm{SO}_{4}$ group on $\mathrm{C}_{4}$ of galactose (Figure 4 ). The peak of 927.76 was the characteristic for $k$-carrageenan without $\mu$-carrageenan and presented 3,6-anhydro-D-galactose group (Figure 4). The stretching vibration of the entire anhydro-glucose ring of antioxidant carrageenan was presented at the peak of $574.79 \mathrm{~cm}^{-1}, 769.60 \mathrm{~cm}^{-1}, 891.11 \mathrm{~cm}^{-1}$, and $927.76 \mathrm{~cm}^{-1}$ (Figure 4), respectively. The peak of $891.11 \mathrm{~cm}^{-1}$ and $842.89 \mathrm{~cm}^{-1}$ were the properties of $\beta$-carrageenan and $j$ carrageenan, respectively (Figure 4). 


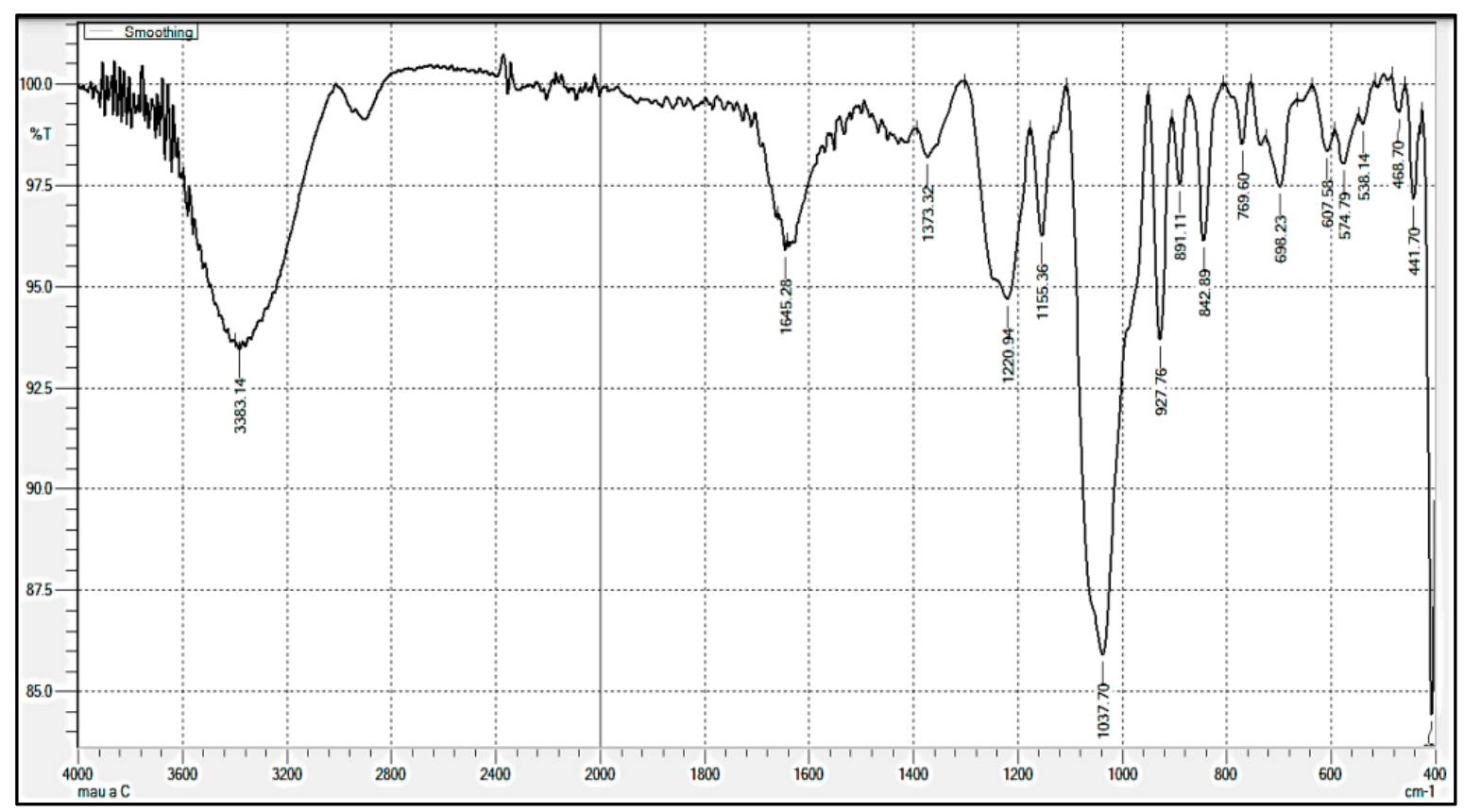

Figure 4. FTIR spectroscopy of antioxidant carrageenan.

GPC is a new solution for the effortless analysis of polymeric compounds in nature and facilitates molecular mass analysis; carrageenan is dissolved in an alkaline medium. Figure 5 shows that antioxidant carrageenan, which was extracted from Eucheuma gelatinae, possessed two fractions, with the average molecular weight of $2.635 \times 10^{6}$ and $2.58 \times 10^{6}$ $\mathrm{g} / \mathrm{mol}$, respectively.

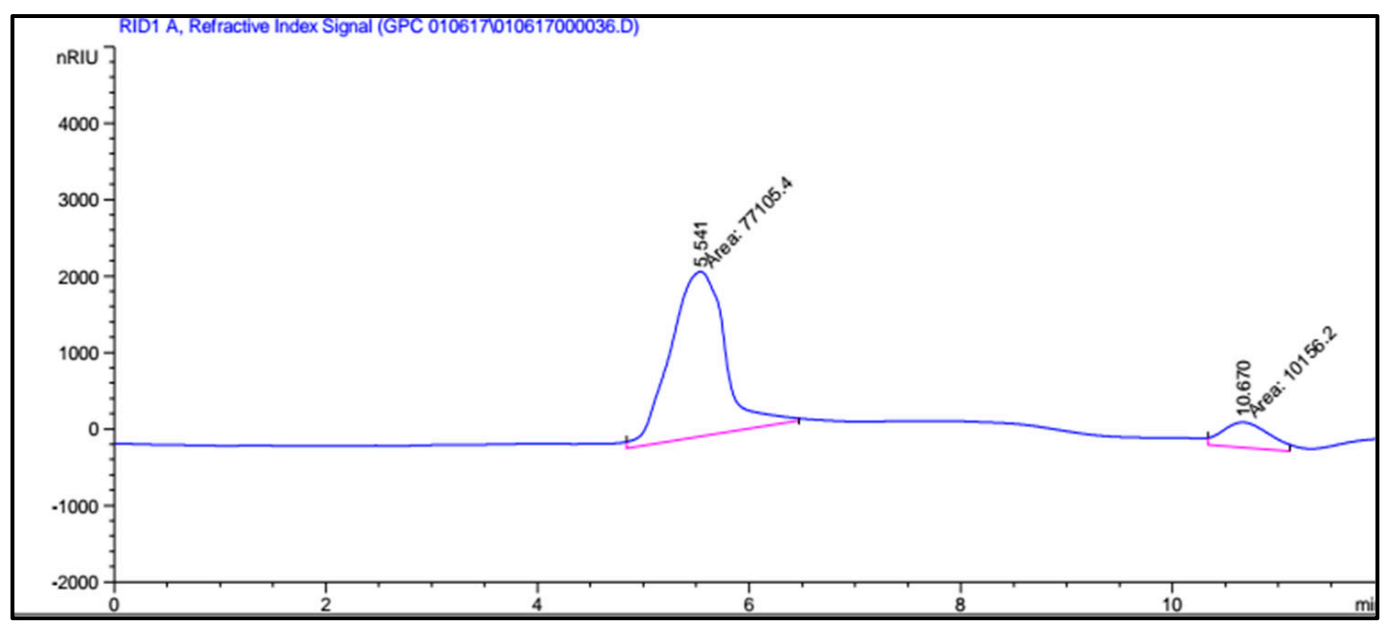

Figure 5. GPC spectroscopy of antioxidant carrageenan.

X-ray diffraction (XRD) is the sole laboratory technique that equips structural information such as chemical composition, crystal structure, crystal size, strain, and layer thickness. As a result, materials researchers use XRD to examine a wide range of materials, from powder X-ray diffraction (XRPD) to solids, thin films, and nanomaterials. In the current study, $X$-ray diffraction was used to analyze the crystal structure of carrageenan. Antioxidant carrageenan had a high purity degree and did not form a crystal structure, exhibited in Figure 6. 


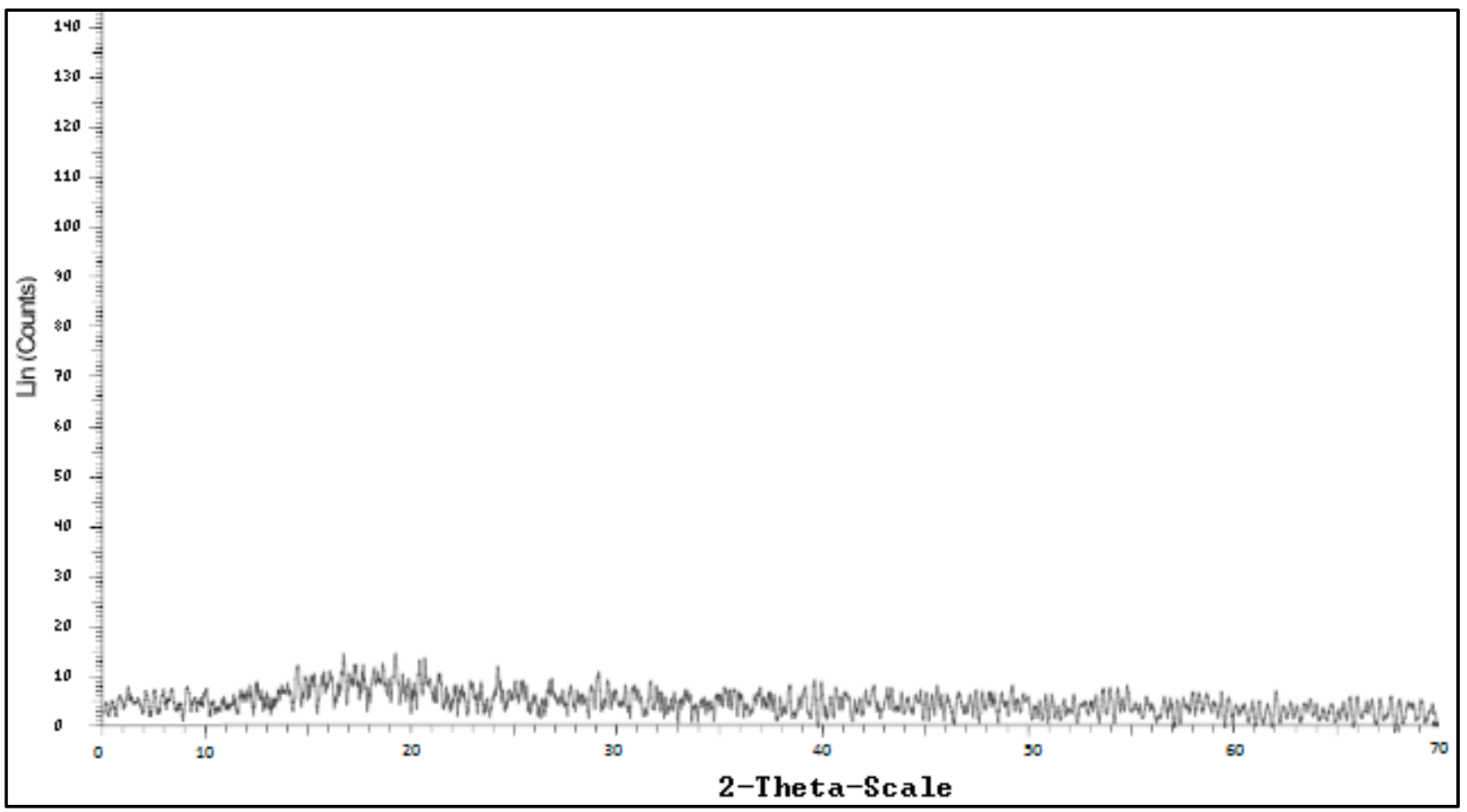

Figure 6. GPC spectroscopy of antioxidant carrageenan.

\section{Discussion}

Purity carrageenan content was collected using solvent $\mathrm{pH} 7$ at 1.54 and 1.32 times, compared to solvent $\mathrm{pH} 10$ and 9, respectively. The highest drop in purity carrageenan content occurred when solvent $\mathrm{pH}$ increased from 8 to 9 , corresponding to $21.09 \%$. In the range of the extracting temperature from $80-100{ }^{\circ} \mathrm{C}$, the temperature increased by $10^{\circ} \mathrm{C}$, and purity carrageenan content increased by $6.8 \%$. At the extracting temperature of $70{ }^{\circ} \mathrm{C}$, the purity carrageenan content was $0.94,0.88$, and 0.85 times, compared to 80,90 , and $100{ }^{\circ} \mathrm{C}$, respectively. The impact of solvent $\mathrm{pH}$ for purity carrageenan content was the descend linear model when solvent $\mathrm{pH}$ increased, however, one of the temperatures was inversed. The change of purity carrageenan content was the quadratic model trend with the maximum peak at $90 \mathrm{~min}$. When the extracting time increased from 30 to $60 \mathrm{~min}$, purity carrageenan content also increased by $18.89 \%$. Increasing of the time from 60 to $90 \mathrm{~min}$, the following increase of purity carrageenan content was only $6.32 \%$. After the extraction at 90 $\mathrm{min}$, purity carrageenan content decreased. The increase ratio of solvent-to-ratio from 20 to $40(v / w)$ led to the increasing purity carrageenan content of 1.42 times. Purity carrageenan content tended parallel to the horizontal axis when the solvent-to-algae ratio increased from $30 / 1$ to $50 / 1(v / w)$. The difference in algae species and extraction methods caused different carrageenan-extracted content, for example, using ohmic heating for carrageenan extraction from Eucheuma spinosum, needing the temperature $\left(95^{\circ} \mathrm{C}\right)$, the time $(240 \mathrm{~min})$, and the solvent-to-algae ratio of 45/1 (v/w) [17]. The study of Andi et al. (2021) [17] exhibited the extraction condition of carrageenan from Eucheuma spinosum higher than in the current study.

The total antioxidant activity and reducing power activity changed according to the increasing solvent $\mathrm{pH}$ linear model trend, similar to purity carrageenan content under the impact of solvent $\mathrm{pH}$. The increase of solvent $\mathrm{pH}$ was from 9 to 10 , and total antioxidant activity and reducing power activity decreased by 55.58 and $35.08 \%$, respectively. The antioxidant change of total antioxidant activity and reducing power activity was similar to purity carrageenan content change under the impact of the extracting temperature. It showed that antioxidant activity was proportional to the purity carrageenan content. The rate of increase in antioxidant activity decreased when the temperature increased. When the extracting temperature increased from $70{ }^{\circ} \mathrm{C}$ to 80,90 , and $100{ }^{\circ} \mathrm{C}$, the ratio of total 
antioxidant activity increased by $27.23,11.03$, and $7.4 \%$, the increasing ratio of reducing power activity corresponded to $30.04,10.36$, and $3.63 \%$. The change of antioxidant activity composed of total antioxidant activity and reducing power activity was proportional to the purity carrageenan content change according to the linear model as the increase of extraction time. When the extracting time was 60,90 , and $120 \mathrm{~min}$, total antioxidant activity increased by $43.26,50.03$, and $61.47 \%$, and the increase of reducing power activity was $27.41,29.86$, and $41.05 \%$, compared to the extracting time for $30 \mathrm{~min}$. The impact of the solvent-to-algae ratio on purity carrageenan content and the antioxidant was similar to that of the extracting time. However, the effect of the raw material solvent ratio on the refined carrageenan content was only evident when changing the raw material solvent ratio from 20 to $30 / 1(v / w)$. The solvent-to-algae ratio impacted antioxidant activity more clearly than the purity carrageenan content. It meant that carrageenan from Eucheuma gelatinae possessed antioxidant activity, and short-chain carrageenan had higher antioxidant activity than long-chain carrageenan. Previous studies had only shown the antioxidant capacity of $\kappa$-carrageenan. For carrageenan from Eucheuma gelatinae, its antioxidant activity was only shown based on the DPPH and ABTS method, and correlation between carrageenan and antioxidant activity [23] was not found. In the current study, the antioxidant activity of beta carrageenan is evaluated based on total antioxidant activity and reducing power activity, also described as the correlation between them. The impact of different extraction conditions on antioxidant carrageenan from Eucheuma gelatinae was not presented in previous studies, but found in the current study.

Previous studies on optimization of carrageenan extraction mainly focused on the objective functions of extraction yield, gel strength, and viscosity of carrageenan on Kappaphycus alverazii and Eucheuma spinosum with alkaline solvent. The input factors were mainly studied to be temperature and time [24,25]. There was only one Chinese notice of Eucheuma gelatinae pretreatment optimization for carrageenan extraction. However, this publication did not address the antioxidant activity of carrageenan. The optimization of the target functions, such as extraction efficiency and antioxidant activity of carrageenan from Eucheuma gelatinae, the survey of solvent $\mathrm{pH}$, temperature, time and solvent-to-material ratio in the determination of optimization domain, and the optimization of three input factors (solvent-to-material ratio, temperature, and time of extraction) in the optimization were presented in the current study. A Box-Behnken design model with a sphere response model had also not been found in studies of carrageenan extraction.

Antioxidant carrageenan from Eucheuma gelatinae in Vietnam possessed the characteristics of gel strength and viscosity higher than carrageenan from Eucheuma sp. in previous studies [24,26]. Sugar compositions of antioxidant carrageenan were noticed in the current study and were one of the few publications on sugar compositions of carrageenan and the only one on the sugar content of the antioxidant carrageenan from Eucheuma gelatinae. The average molecular weight of antioxidant carrageenan in the current study was higher than the results obtained by Nishinaria and Watase (1992) [27] and Ahmed et al. (2018) [28].

The results showed the existence of $\beta$-carrageenan in peak $891 \mathrm{~cm}^{-1}$ in the spectrum range of $580-3420 \mathrm{~cm}^{-1}$, [29], and the appearance of peak $820 \mathrm{~cm}^{-1}$ related to $\gamma$-carrageenan. The results were interesting compared to the previous studies. Algae species differently led in structure and functional groups composition in carrageenan [30], for example, l-carrageenan in Eucheuma serra [31], and $\kappa$-carrageenan in Eucheuma cottonii [24]. The peak of $842 \mathrm{~cm}^{-1}$ and $925 \mathrm{~cm}^{-1}$ are $\mathrm{C}-\mathrm{O}-\mathrm{SO}_{4}$ group presence on $\mathrm{C} 4$ of galactose and 3,6-anhydro-D-galactose [18]. The entire anhydro-glucose ring achieved the stretching vibration at $573 \mathrm{~cm}^{-1}, 760 \mathrm{~cm}^{-1}, 858 \mathrm{~cm}^{-1}$, and $928 \mathrm{~cm}^{-1}$ [32], respectively. The spectra of $848 \mathrm{~cm}^{-1}$ and $891 \mathrm{~cm}^{-1}$ appeared as C-4 sulfate of the $j$-carrageenan and $\beta$-carrageenan, respectively [33]. 


\section{Materials and Methods}

\subsection{Source of the Plant Material}

Red algae Eucheuma gelatinae was collected from Ninh Hai district, Ninh Thuan province, Vietnam in April 2017.

\subsection{Sample Preparation}

Eucheuma gelatinae was selected, washed and dried until the humidity was lower than $8 \%$. Next, the seaweed was crushed to a size of $2-3 \mathrm{~cm}$ for further study.

\subsection{Extraction of Carrageenan}

Carrageenan was extracted by agitating maceration with classical experimental design, fixing an independent variable and running the remaining variables.

For surveying solvent $\mathrm{pH}$ from 7 to 10 with a jump $(\delta) 1$, temperature, time, and the ratio of solvent-to-algae of extraction were fixed, corresponding to $80^{\circ} \mathrm{C}, 60 \mathrm{~min}$, and $30 / 1$ $(v / w)$, respectively.

For surveying the extracting temperature from 70 to $100{ }^{\circ} \mathrm{C}$ with $\delta 10^{\circ} \mathrm{C}$, time and the ratio of solvent-to-algae of extraction were similar to the study on solvent $\mathrm{pH}$ and collection of solvent $\mathrm{pH}$ from the above results.

For surveying the extracting time from 30 to $120 \mathrm{~min}$ with $\delta 30 \mathrm{~min}$, the ratio of solvent-to-algae of extraction was 30/1 $(v / w)$. $\mathrm{pH}$ solvent and the extracting temperatures were from the above results.

For surveying the solvent-to-algae ratio from 20 to $50(v / w)$ with $\delta 10(v / w)$, three independent variables (solvent $\mathrm{pH}$, temperature, and time of extraction) were from the above results.

All extracts were filtered through Whatman No 1. and precipitated using $96 \%$ ethanol. The residues were dried at $40{ }^{\circ} \mathrm{C}$ for carrageenan collection. Carrageenan was analysed for the purity content and antioxidant activity.

\subsection{Optimization of Carrageenan Extraction}

The optimization of carrageenan extraction was based on the experiment design model of Box-Behnken with four input factors, including temperature $\left(X_{1},{ }^{\circ} \mathrm{C}\right)$, time $\left(X_{2}\right.$, minutes), the solvent-to-material ratio $\left(X_{3}, v / w\right)$, and three target functions such as, for example, carrageenan purity degree $\left(Y_{1}, \%\right)$, total antioxidant $\left(Y_{2}, \mathrm{mg}\right.$ ascorbic acid equivalent/g $\mathrm{DW})$, and reducing power $\left(Y_{3}, \mathrm{mg} \mathrm{FeSO}_{4} / \mathrm{g} \mathrm{DW}\right)$. The optimal experimental domain of four input factors and the independent-to-coding variable conversion are presented in Table 4. The experimental design included 12-factor experiments and three replicate experiments at the center of the plan (Table 5). The target functions were selected and based on the combined results of independent variables in Table 5. The experiments were randomly carried out to minimize the effects of unusual changes in the observations. The variables are coded according to the following equation:

$$
x=\frac{\left(X_{i}-X_{0}\right)}{\Delta X}
$$

wherein $x$ is the code variable, $X_{i}$ is the real variable, $X_{0}$ is the central experiment variable, and $\Delta X$ is the difference between the maximum value of the real variable and the value of $X_{0}$. The mathematical equation corresponding to the Box-Behnken experimental model is as follows:

$$
Y=\beta_{0}+\sum_{i=1}^{3} \beta_{i} X_{i}+\sum_{i=1}^{3} \beta_{i i} X_{i}^{2}+\sum_{i=1}^{2} \sum_{j=1+1}^{3} \beta_{i j} X_{i} X_{j}+\varepsilon
$$

Requirement of objective functions:

$Y_{1}$ : extraction efficiency of carrageenan (\%): $\max$

$Y_{2}$ : total antioxidant activity (mg ascorbic acid equivalent/g DW): $\max$

$Y_{3}$ : reducing power activity $\left(\mathrm{mg} \mathrm{FeSO}_{4}\right.$ equivalent/g DW): max 
Table 4. The conversion between code variables and reality variables.

\begin{tabular}{cccc}
\hline \multirow{2}{*}{ Input Factor (Independent Variable) } & \multicolumn{3}{c}{ Code Variable } \\
\cline { 2 - 4 } & $\mathbf{- 1}$ & $\mathbf{0}$ & $\mathbf{1}$ \\
\hline Extracting temperature $\left(X_{1},{ }^{\circ} \mathrm{C}\right)$ & 70 & 85 & 100 \\
Extracting time $\left(X_{2}\right.$, minutes) & 30 & 75 & 120 \\
Solvent-to-material ratio $\left(X_{3}, v / w\right)$ & 20 & 35 & 50 \\
\hline
\end{tabular}

Carrageenan was collected in the condition of optimization extraction and analyzed for rheological (gel strength and intrinsic viscosity) and physical-chemistry characteristics (molecular weight, functional groups, crystal structure, and sugar composition).

Table 5. Experiment design and the results.

\begin{tabular}{ccccccccc}
\hline & \multicolumn{3}{c}{ Actual Variable } & \multicolumn{3}{c}{ Coded Variable } & \multicolumn{2}{c}{ Target Function } \\
\cline { 2 - 7 } Std & $\boldsymbol{X}_{\mathbf{1}}$ & $\boldsymbol{X}_{\mathbf{2}}$ & $\boldsymbol{X}_{\mathbf{3}}$ & $\boldsymbol{x}_{\mathbf{1}}$ & $\boldsymbol{x}_{\mathbf{2}}$ & $\boldsymbol{x}_{\mathbf{3}}$ & $\boldsymbol{Y}_{\mathbf{1}}$ & $\boldsymbol{Y}_{\mathbf{2}}$ \\
\hline 1 & 70 & 30 & 35 & -1 & -1 & 0 & & \\
2 & 100 & 30 & 35 & +1 & -1 & 0 & \\
3 & 70 & 120 & 35 & -1 & +1 & 0 & \\
4 & 100 & 120 & 35 & +1 & +1 & 0 & $Y_{i j}$ \\
5 & 70 & 75 & 20 & -1 & 0 & -1 & \\
6 & 100 & 75 & 20 & +1 & 0 & -1 & \\
7 & 70 & 75 & 50 & -1 & 0 & +1 & \\
8 & 100 & 75 & 50 & +1 & 0 & +1 & \\
9 & 85 & 30 & 20 & 0 & -1 & -1 & \\
10 & 85 & 120 & 20 & 0 & +1 & -1 & \\
11 & 85 & 30 & 50 & 0 & -1 & +1 & \\
12 & 85 & 120 & 50 & 0 & +1 & +1 & \\
13 & 85 & 75 & 35 & 0 & 0 & 0 & \\
14 & 85 & 75 & 35 & 0 & 0 & 0 & \\
15 & 85 & 75 & 35 & 0 & 0 & 0 & \\
\hline
\end{tabular}

4.5. Determination of the Content and the Extraction Efficiency of Carrageenan

\subsubsection{Purity Carrageenan Content}

Purity carrageenan content is calculated based on the following equation:

$$
\text { Purity carrageenan content }\left(C_{P}, \%\right)=\frac{C_{R}-H_{C}-A_{C}}{W_{A}}(\%)
$$

where in $C_{R}(\%)$ is the dry weight of carrageenan after extraction as described in Section 4.3. The humidity content of $C_{R}$ is $H_{C}$, which is determined according to the drying method at $105^{\circ} \mathrm{C}$ until constant weight. $W_{A}$ is the dried algae powder. The ash content of $C_{R}$ is $A_{c}$, which is calculated and based on the white ash weight of the material after being calcined at $650{ }^{\circ} \mathrm{C}$.

\subsubsection{Extraction Efficiency of Carrageenan}

The extraction efficiency of carrageenan was determined according to the following equation:

$$
\begin{gathered}
\text { EEC }(\%)=\frac{C_{p}}{\text { Carrageenan in initial algae }(\%)} \\
\text { Carrageenan in initial algae }=W_{A}-H_{A}-A_{A}-\text { Protein }_{A}-\text { Lipid }_{A}-\text { Cellulose }_{A}
\end{gathered}
$$

where in:

$W_{A}$ : the dried algae powder $(\mathrm{g})$;

$H_{A}$ : humidity content of algae powder (g); dried at $105^{\circ} \mathrm{C}$.

$A_{A}$ : ash content of algae powder $(\mathrm{g})$; calcined at $650^{\circ} \mathrm{C}$. 
Protein $_{A}$ : protein content of algae powder $(\mathrm{g})$; determined based on the method of Lowry.

Lipid $_{A}$ : lipid content of algae powder (g); determined based on the soxhlet method.

Cellulose $_{A}$ : cellulose content of algae powder $(\mathrm{g})$;

\subsection{Detemination of Antioxidant Activity}

\subsubsection{Total Antioxidant Activity}

$100 \mu \mathrm{L}$ extract, in turn, was added to $900 \mu \mathrm{L}$ of distilled water and solution A (0.6 M $\mathrm{H}_{2} \mathrm{SO}_{4}, 28 \mathrm{mM}$ sodium phosphate and $04 \mathrm{mM}$ ammonium molybdate). The mixture was vortexed and kept for $90 \mathrm{~min}$ at $95^{\circ} \mathrm{C}$ and then measured at the wavelength of $695 \mathrm{~nm}$ with an ascorbic acid standard [34].

\subsubsection{Reducing Power Activity}

The reducing power activity was determined according to the method of Zhu et al. (2002) [35]. Firstly, $0.5 \mathrm{~mL}$ phosphate buffer at pH 7.2 was added to $500 \mu \mathrm{L}$ extract. Secondly, $0.2 \mathrm{~mL}$ of $1 \% \mathrm{~K}_{3}\left[\mathrm{Fe}(\mathrm{CN})_{6}\right]$ was added to the compound. The compound was kept at $50{ }^{\circ} \mathrm{C}$ for $20 \mathrm{~min}$. Thirdly, $500 \mu \mathrm{L}$ of $10 \% \mathrm{CCl}_{3} \mathrm{COOH}$ with $300 \mu \mathrm{L}$ distilled water and $80 \mu \mathrm{L}$ of $0.1 \% \mathrm{FeCl}_{3}$ were added. Finally, the compound was measured at $655 \mathrm{~nm}$ with the standard substance $\mathrm{FeSO}_{4}$.

\subsection{Determination of Rheological Characteristics}

\subsubsection{Gell Strength}

Carrageenan gel strength was measured with a Brookfield rheometer and the maintenance of samples at $20{ }^{\circ} \mathrm{C}$. Samples were prepared by dissolving $1.7 \mathrm{~g}$ of carrageenan powder in $98.3 \mathrm{~mL}$ of distilled water at $80^{\circ} \mathrm{C}$ to form a $1.5 \%$ carrageenan solution. $\mathrm{KCl}$ was then added until reaching $0.1 \% \mathrm{KCl}$ solution and soaking to $20^{\circ} \mathrm{C}$ for $2.5 \mathrm{~h}$. Carrageenan gel was continuously cut into slices with a thickness of $1.5 \mathrm{~cm}$ and put into the rheometer for measurement.

\subsubsection{Intrinsic Viscosity}

The viscosity of $1.5 \%$ carrageenan solution at $80^{\circ} \mathrm{C}$ was measured with a Brookfield rheometer.

\subsection{Determination of Physic-Chemistry Characterization}

\subsubsection{Sugar Compositions}

The sugar composition determination of antioxidant carrageenan was according to the GC-FID method on Agilent's $6890 \mathrm{~N}$ gas chromatograph (USA) that was composed of an automatic sample injector, an injection chamber, a column furnace, a flame ionization detector (FID), and an HP5 MS column $(30 \mathrm{~m} \times 0.25 \mathrm{~m} \times 0.25 \mathrm{~m})$. The chamber temperature was set at $280{ }^{\circ} \mathrm{C}$ with the line split ratio of $0 / 1$. The program temperature column was set at $100{ }^{\circ} \mathrm{C}$ with a $20^{\circ} \mathrm{C} / \mathrm{min}$ rate for getting $325^{\circ} \mathrm{C}$ and kept for $10 \mathrm{~min}$, and then the probe temperature at $300{ }^{\circ} \mathrm{C}$ and carried gas speed at $01 \mathrm{~mL} / \mathrm{min}$. Derivation process: The sample was hydrolyzed in $1.5 \mathrm{M} \mathrm{HCl}$, then poured to $10 \mathrm{~mL}$ of the cylinder by acetic anhydride, and the compound was finally injected into the GC system.

\subsubsection{Molecular Weight}

The average molecular weight of carrageenan was measured with gel permeation chromatography, using a model YL9100 GPC.

\subsubsection{Functional Groups}

The samples and anhydrous $\mathrm{KBr}$ were mixed according to the ratio of $\mathrm{KBr}$-to-sample of 98:2 $(w / w)$. The mixture was then measured on a Bruker FT-IR spectrometer ALPHA with a wavelength range from 4000 to $500 \mathrm{~cm}^{-1}$. Finally, the results were analysed on OPUS 7.0 software (Bruker, Ettlingen, Germany). 


\subsubsection{Crystal Structure}

The crystal structure of carrageenan was measured on a Brucker-Germany instrument, model D8 Advance, which met the ISO 9001:2000 international standards, in addition to standards for radiation safety and European CE standards for electrical safety. $0.5 \mathrm{~g}$ of carrageenan was finely ground in an agate mortar and pestle and placed in a special tray of a polycrystalline powder diffraction apparatus. Samples in the tray were flat and spread evenly over the tray surface. The sample holder mounted on an incident beam (narrow, monochromatic, parallel X-ray beam projected onto the sample). X-ray was rotated at an angle theta $(\theta)$ for the incident ray, and obtained the dispersion of $X$-ray by the detectorright. The sodium iodide (NaI) flicker detector would rotate $2 \theta$ from $5-70^{\circ}$. One sample rotation was $0.03^{\circ}$ and the single point diffraction time was one second. The measuring temperature of samples was at $25^{\circ} \mathrm{C}$.

\subsection{Statistical Analysis}

All experiments were undertaken in triplicate and exhibited under mean $\pm \mathrm{SD}$ with a significant level $(p<0.05)$. Analysis of statistics, ANOVA, and regression was calculated using the software MS. Excel 2013 and Design Expert 13. Duncan method was used for the movement of the non-normal value.

\section{Conclusions}

In summary, surveying and condition optimization of carrageenan extraction from Eucheuma gelatinae with the target functions such as purity carrageenan content, total antioxidant activity, and reducing power activity were performed in this study. Antioxidant carrageenan extracted at the optimal condition was evaluated, including the rheology and physicochemical properties. Antioxidant carrageenan contained rhamnose, mannose, glucose, fucose, and xylose. The molecular weight of carrageenan reached an average value of $2.635 \mathrm{e}^{6}$ and $2.58 \mathrm{e}^{6} \mathrm{~g} / \mathrm{mol}$. The solvent-to-algae ratio had the least effect on the objective functions. Antioxidant carrageenan from Eucheuma gelatinae had intrinsic viscosity $(263.02 \mathrm{cps})$ and gel strength $\left(487.5 \mathrm{~g} / \mathrm{cm}^{2}\right)$, and did not exist in the crystal. At the optimization condition $\left(82.35{ }^{\circ} \mathrm{C}\right.$ for $115.35 \mathrm{~min}$ with the solvent-to-algae ratio of $36.42(v / w))$, target functions were predicted such as carrageenan yield of extraction $(87.56 \pm 5.61, \%)$, total antioxidant activity $(71.95 \pm 5.32, \mathrm{mg}$ ascorbic acid equivalent $/ \mathrm{g}$ $\mathrm{DW})$, and reducing power activity $\left(89.84 \pm 5.84, \mathrm{mg} \mathrm{FeSO}_{4}\right.$ equivalent/g DW)). The highest value of purity carrageenan content is $42.68 \pm 2.37(\%, \mathrm{DW})$, and it has potential in the food and pharmaceutical industries.

Supplementary Materials: The following supporting information can be downloaded online. Figure S1. FTIR spectroscopy of antioxidant carrageenan.

Author Contributions: Conceptualization, H.T.H., D.X.C. and L.H.T.; methodology, D.X.C. and P.T.T; software, D.H.D.; validation, V.T.M. and D.T.T.T.; formal analysis, D.T.T.T. and L.H.T.; investigation, H.T.H. and D.H.D.; resources, D.X.C. and D.T.T.T.; data curation, H.T.H. and L.H.T.; writing-original draft preparation, P.T.T. and V.T.M.; writing-review and editing, D.X.C. and V.T.M.; visualization, P.T.T. and H.T.H.; supervision, D.X.C. and D.T.T.T.; project administration, L.H.T. and D.H.D.; funding acquisition, H.T.H., P.T.T. and V.T.M. All authors have read and agreed to the published version of the manuscript.

Funding: This research received no external funding.

Institutional Review Board Statement: Not applicable.

Informed Consent Statement: Not applicable.

Data Availability Statement: Datas are available from the authors.

Acknowledgments: Thankful for the support of Tran Thi Thanh Van in the current study.

Conflicts of Interest: The authors declare that they have no conflict of interest. 


\section{References}

1. Bixler, H.; Porse, H. A decade of change in the seaweed hydrocolloids industry. J. Appl. Phycol. 2011, 23, 321-335. [CrossRef]

2. FAO. The state of the world fisheries and aquaculture 2020. Sustain. Action Rome 2020, 244. [CrossRef]

3. Brakel, J.; Sibonga, R.C.; Dumilag, R.V.; Montalescot, V.; Campbell, I.; Cottier-Cook, E.J.; Ward, G.; Le, M.V.; Liu, T.; Msuya, F.E.; et al. Exploring, harnessing and conserving marine genetic resources towards a sustainable seaweed aquaculture. Plants People Planet 2021, 3, 337-349. [CrossRef]

4. FAO. The global status of seaweed production, trade and utilization. Globefish Res. Programme 2018, 24, 124.

5. Available online: https://www.fao.org/3/x5819e/x5819e06.htm (accessed on 30 November 2016).

6. Gómez-Ordóñez, E.; Jiménez-Escrig, A.; Rupérez, P. Bioactivity of sulfated polysaccharides from the edible red seaweed Mastocarpus stellatus. Bioact. Carbohydr. Diet. Fibre 2014, 3, 29-40. [CrossRef]

7. Besednova, N.; Zaporozhets, T.; Kuznetsova, T.; Makarenkova, I.; Fedyanina, L.; Kryzhanovsky, S.; Malyarenko, O.; Ermakova, S. Metabolites of seaweeds as potential agents for the prevention and therapy of influenza infection. Mar. Drugs 2019, 17, 373. [CrossRef]

8. Necas, J.; Bartosikova, L. Carrageenan: A review. Vet. Med. 2013, 58, 187-205. [CrossRef]

9. Mingjin, Z.; Liming, G.; Yongbo, L.; Yaxin, Zi.; Xinying, Li.; Defu, L.; Changdao, M. Preparation, characterization and antibacterial activity of oxidized K-carrageenan. Carbohydr. Polym. 2017, 174, 1051-1058. [CrossRef]

10. Ratih, P.; Se-Kwon, K. Biological Activities of Carrageenan. Adv. Food Nutr. 2014, 72, 113-124. [CrossRef]

11. Maxim, K.; Vladlena, T.; Aleksandra, K.; Maria, B.; Rodion, K.; Ekaterina, L.; Igor, B.; Yuri, K. Antitumor potential of carrageenans from marine red algae. Carbohydr. Polym. 2020, 246, 116568. [CrossRef]

12. Eduardas, C.; Aleksandra, A.; Kalitnik, Y.A.K.; Manoj, S.G.M.R.; Anant, A.; Anna, O.K. Immunomodulating properties of carrageenan from Tichocarpus crinitus. Inflammation 2020, 43, 1387-1396.

13. Xia, Q.; Wenwen, Z. Antihyperglycemic and antihyperlipidemic effects of low-molecular-weight carrageenan in rats. Open Life Sci. 2018, 13, 379-384. [CrossRef]

14. Tobacman, J.K. Review of harmful gastrointestinal effects of carrageenan in animal experiments. Environ. Health Perspect. 2001, 109, 983-994. [CrossRef]

15. Edisson-Mauricio, P.-Q.; Roberto, R.-C.; María-Dolores, V. Carrageenan: Drug delivery systems and other biomedical applications Mar. Drugs 2020, 18, 583-622. [CrossRef]

16. Tarman, U.S.; Joko, S.; Linawati, H. Carrageenan and its enzymatic extraction. In Kustiariyah Encyclopedia of Marine Biotechnology: Five Volume Set, 1st ed.; John Wiley \& Sons Ltd.: Hoboken, NJ, USA, 2020.

17. Andi, H.; Meta, M.; Amran, L.; Metusalach, M. Extraction of carrageenan from Eucheuma spinosum using ohmic heating: Optimization of extraction conditions using response surface methodology. Food Sci. Technol. 2021, 41, $928-937$.

18. Zainab, M.A.-N.; Ahmed, A.-A.; Insaaf, A.-M. The effect of extraction conditions on chemical and thermal characteristics of kappa-carrageenan extracted from Hypnea bryoides. J. Mar. Sci. 2019, 2019, 5183261. [CrossRef]

19. Siti, M.; Widiyastuti, W.; Hideki, K.; Sugeng, W.; Motonobu, G. Pressurized hot water extraction of carrageenan and phenolic compounds from Eucheuma cottonii and Gracilaria sp.: Effect of extraction conditions. ARPN J. Eng. Appl. 2019, 14, 3113-3123.

20. Mariel, G.T.; Lucille, V.A.; Virgilio, D.E.; Drexel, H.C. Ultrasound-assisted depolymerization of kappa-carrageenan and characterization of degradation product. Ultrason. Sonochem. 2021, 73, 105540. [CrossRef]

21. Vázquez-Delfín, E.; Robledo, D.; Freile-Pelegrín, Y. Microwave-assisted extraction of the Carrageenan from Hypnea musciformis (Cystocloniaceae, Rhodophyta). J. Appl. Phycol. 2014, 26, 901-907. [CrossRef]

22. Deng, C.-M.; Wu, Z.-J.; He, L.-Z.; Zhang, G.-G.; Wu, Y.-L.; Wen, Y.-M.; Kang, X.-H. Technological optimization of alkali pretreatment in the carrageenan extraction from Eucheuma gelatinae. Sci. Technol. Food Ind. 2017, 22, 178-183. [CrossRef]

23. Tran, T.T.V.; Vo, M.N.H.; Cao, T.T.H.; Phan, T.H.T.; Tran, M.D.; Quach, T.M.T. Structural characteristics and biological activity of sulfated polysaccharide from red algae Betaphycus gelatinus. Vietnam J. Sci. Technol. 2020, 58, 252-260.

24. Vanessa, W.; Sabrina, M.D.C.; Paulo, J.O.; Leila, H.; Pedro, L.M.B. Optimization of the extraction of carrageenan from Kappaphycus alvarezii using response surface methodology. Food Sci. Technol. 2012, 32, 812-818.

25. Chen, F.; Peng, J.; Lei, D.; Liu, J.; Zhao, G. Optimization of genistein solubilization by k-carrageenan hydrogel using response surface methodology. Food Sci. Hum. Wellness 2013, 2, 124-131. [CrossRef]

26. Joseph, W.; Bolton, J.J.; Derek, K.; Lincoln, R. Seasonal changes in carrageenan yield and gel properties in three commercial eucheumoids grown in southern Kenya. Bot. Mar. 2006, 49, 208-215.

27. Nishinari, K.; Watase, M. Effects of sugars and polyols on the gel-sol transition of kappa-carrageenan gels. Thermochim. Acta 1992, 206, 149-162. [CrossRef]

28. Ahmed, A.-A.; Pothiraj, C.; Abdullah, A.-M.; Insaaf, A.-M.; Mohammad, S.R. Characterization of red seaweed extracts treated by water, acid and alkaline solutions. Int. J. Food Eng. 2018, 14, 1-9.

29. Pereira, L. Identification of phycocolloids by vibrational spectroscopy. In World Seaweed Resources-An Authoritative Reference System; Critchley, A.T., Ohno, M., Largo, D.B., Eds.; ETI Information Services Ltd., UNESCO: Paris, France, 2006.

30. Greer, C.W.; Yaphe, W. Characterization of hybrid (Beta-Kappa-Gamma) carrageenan from Eucheuma gelatinae J. Agardh (Rhodophyta, Solieriaceae) using carrageenases, infrared and 13C-nuclear magnetic resonance spectroscopy. Bot. Mar. 1984, 27, 473-478. [CrossRef] 
31. Li-Hwa, L.; Masakuni, T.; Fujiya, H. Isolation and characterization of $l$-carrageenan from Eucheuma serra (Togekirinsai). J. Appl. Glycosci. 2000, 47, 303-310.

32. Fang, J.; Fowler, P.; Sayers, C.; Williams, P. The chemical modification of a range of starches under aqueous reaction conditions. Carbohydr. Polym. 2004, 55, 283-289. [CrossRef]

33. Aimei, W.; Nahidul, I.M.; Xiaojuan, Q.; Hongxin, W.; Yaoyao, P.; Chaoyang, M. Purification, identification, and characterization of D-galactose-6-sulfurylase from marine algae (Betaphycus gelatinus). Carbohydr. Res. 2014, 388, 94-99.

34. Prieto, P.; Pineda, M.; Aguilar, M. Spectrophotometric quantitation of antioxidant capacity through the formation of a phosphomolybdenum complex: Specific application to the determination of vitamin E. Anal. Biochem. 1999, 269, 337-341. [CrossRef]

35. Zhu, Q.Y.; Hackman, R.M.; Ensunsa, J.L.; Holt, R.R.; Keen, C.L. Antioxidative activities of oolong tea. J. Agric. Food Chem. 2002, 50, 6929-6934. [CrossRef] 